\title{
Research in Distance Education: A Status Report
}

\author{
Farhad Saba
}

\begin{abstract}
Since the 1950s and expansion of social science research, distance education has been studied in comparison to face-to-face or classroom instruction. Although researchers continue to conduct comparative studies, their usefulness in revealing more information has diminished over the years; invariably, they have returned a "no significant difference" result between various forms of instruction. In recent years, researchers have moved beyond atheoretical, experimental comparative studies and have introduced new methods, such as discourse analysis, and in-depth interview of learners. These new methods overcome many methodological and theoretical limitations of the physical science view of distance education. These studies have further revealed the complexity of distance education, indicating the many variables involved in the concept. Starting with the core issue of instructional interaction and grounded on the theory of transactional distance, a new strand of research using methods related to systems dynamics, hierarchy and complexity theories, promises a more comprehensive understanding.
\end{abstract}

\section{What is Research?}

The purpose of this article is to present a coherent view of the state of research in distance education. As such, it is appropriate to clarify what is meant by research first.

Traditionally, research has been synonymous with the scientific method; and in education, until recently, experimentation has been the dominant mode of inquiry (Best, 1977). Experimental research was the method by which physical sciences obtained their dramatic results in the last century and achieved their current status.

Originally designed for the laboratory where the environment could be carefully controlled, experimental research found its way to social sciences where laboratory conditions were difficult, if not impossible to obtain. As such, researchers adopted the idea of random selection of their subjects to control for the effect of the experimental variable. In other words, if members of only one of two groups of randomly selected subjects are exposed to an experimental variable (e.g., distance education), and if the test scores of the experimental group show 
a difference as compared to the control group, then the chances are that the difference can be attributed to the experimental variable.

However, in education research most classrooms are pre-selected by factors other than experimental requirements. As such, the concept of experimental research was modified and acquired the name of quasi-experimental research to reflect this change. So far, distance education research has been dominated by quasiexperimental research which compares the effectiveness of distance education to classroom instruction, face-to-face education, or traditional education.

\section{Comparative Studies}

Since the rapid expansion of instructional television in the 1950s and the ascendance of social science research after the Second World War, comparing distance education with the so-called face-to-face education has been a favorite of education researchers. In the 1960s, Wilbur Schramm conducted studies which compared instructional television (ITV) with classroom instruction. Also, Schramm (1962) summarized the results of more than 400 "scientifically designed and statistically treated comparisons of ITV and classroom teaching" (p. 66). He concluded: "we can say confidently that students learn from it, and that they learn fast and efficiently" (p. 66). Furthermore, "the conclusion has been "no significant difference' between learning from television, and from classroom teaching" (p. 66).

After Schramm arrived at this conclusion many other researchers have compared classroom instruction to distance education. A recent example is a study conducted by Johnson, Aragon, Shaik, and Palma-Rivas (2000). Researchers in this study compared learning outcomes of an online course with a similar course taught face-to-face. The study concluded that "there was no difference between the two course formats in several measures of learning outcomes" (Johnson et al., 2000, p. 29). Wetzel, Radtke, and Stern (1994) have summarized the results of comparative studies until the mid 1990s. Invariably, comparative studies of distance education and classroom instruction show "no statistically significant difference." Another recent meta-analysis of 19 studies out of an original pool of 700, which met the carefully selected criteria of authors, Machtmes and Asher (2000) confirmed previous conclusions that "there does not appear to be a difference in achievement between distance and traditional learners" (p. 43).

\section{An Absence of Theory}

Absent from most comparative research in distance education is a discussion of theoretical foundations of the field. Research questions are rarely posed within

International Review of Research in Open and Distance Learning 
a theoretical framework or based on its fundamental concepts and constructs. Although research within a theoretical framework is not a requirement for inductive inquiry, a post facto theoretical discussion of research results would be helpful in making studies relevant to the work of other researchers, and possibly even to the practitioners in the field. Comparative researchers, however, have shown little or no interest in the theoretical literature of the field either before or after conducting their studies.

\section{Theory-based Research}

In the past ten years, however, a few researchers have conducted rigorous studies that are based on theoretical foundations of the field, or theories of fields closely related to distance education. Fulford and Zhang (1993) studied learner perception of interaction in instruction and concluded that perception of the level of interaction is a critical predictor of learner satisfaction. They stated "overall interaction dynamics may have a stronger impact on learners' satisfaction than strictly personal participation. Vicarious interaction may result in greater learner satisfaction than would the divided attention necessary to ensure the overt engagement of each participant" (Fulford \& Zhang, 1993, p. 19). The ramification of this conclusion for instructional design is to devise strategies to increase and improve learner perception of overall interaction.

Gunawardena (1995) studied the ramification of social presence theory for community building in computer mediated conferencing (CMC). She concluded: "in spite of the low social context cues of the medium, student perceptions of the social and human qualities of the medium will depend on the social presence created by the instructors/moderators and the online community" (Gunawardena, 1995, p. 164). Tsui and Ki (1996) studied social factors affecting computer mediated communication at the University of Hong Kong. The study revealed that communications among participants were bilateral. Some participants stated that they were reluctant to enter a dialog started by two participants, since

they might have been considered as "intruders." Also, researchers pointed to the relative lack of knowledge of the participants about CMC, highlighting earlier findings by Fulford and Zhang (1993), as well as Gunawardena (1995) that interaction strategies must be built into the design of a course or instructional session for it to be effective.

McDonald and Gibson (1998) studied group development in asynchronous computer conferencing through patterns of interpersonal interaction of participants. They concluded that participants could deal with and resolve interpersonal issues in an asynchronous teaching and learning environment and form a cohesive working group.

Chen and Willits (1999) conducted their study in a synchronous videoconferenc-

International Review of Research in Open and Distance Learning 
ing environment, and showed that the concept of interaction in this and other similar environments is multidimensional and includes "in-class discussion, outof-class electronic communication, and out-of-class face-to-face interaction" (p. 61). The study was grounded in Moore's theoretical analysis of independent learning as well as interaction in distance education, classified into three categories of teacher-student, student-instructional material, and student-student interactions (Moore, 1989).

\section{Interaction: A Common Theme}

A common theme in distance education research is the concept of interaction, which indicates its centrality in conceptualizing the process of teaching and learning. Furthermore, these studies are mostly paradigmatic. That is, their discussion of interaction transcends the idea of distance in its physical sense, and embraces the discussion of teaching and learning in general. The fact that in mediated education the teacher and learner might be physically separated is secondary to the consideration of factors affecting quality of their interaction. By being paradigmatic, this line of research also negates the implied assumption in most comparative studies that there is meaningful interaction in the classroom merely by the virtue of the physical proximity of the teacher and the student.

\section{Beyond the Confines of the Experimental Method}

Another consideration in distance education research is its methodology. The definition of research presented at the beginning of this article was limited to the transference of experimental method from physical to social sciences. The pure experimental method, it was mentioned, had to be modified to quasiexperimental to fit the special consideration of education research. In the new lines of research outlined above, new methods are employed which, although empirical and data-driven, go beyond the narrow confines of experimentation. These new methods cast a wider net for capturing the data generated by the interaction between the teacher and the learner in both of its qualitative and quantitative forms.

These researchers used student self-reporting through a survey study, (Fulford \& Zhang, 1993; Gunawardena, 1995), extensive interviewing of students (McDonald \& Gibson, 1998), conversation and discourse analysis (Chen \& Willits 1999; Tsui \& Ki, 1996) or a combination of these methods to collect the necessary data. These methods indicate a clear break from the traditional scientific method and experimental studies for understanding important factors in distance teaching and learning. Furthermore, these studies are focused on a smaller group of subjects, but take a deeper look at the subjects' verbal and written behaviors. This

International Review of Research in Open and Distance Learning 
is in sharp contrast to the methods employed by quasi-experimental researchers who sought to eliminate individual differences between the control and experimental groups in order to measure and demonstrate the effect of the treatment. This is an important step in refining research methods in distance education, and capturing a wider and richer range of data.

\section{Theory Building and Research}

Researchers, therefore, are showing increased attention to methodological issues, within the framework of the appropriate theoretical foundations to their studies. This is apparent from theoretical and methodological articles which have been published in recent years. These strands of literature are analytical in nature and provide the necessary interplay between theory and research which a maturing field needs in order to bolster its foundations.

For example, Smith and Dillon (1999) revisited the issue of comparing distance learning and classroom learning and suggested a framework for "defining categories of attributes embedded within each delivery system and the media used by the delivery system that may support learning in different ways" (p. 19). The authors thought that a new set of categories and "clearly defined constructs of both media and delivery systems" (Smith \& Dillon, p. 20) would facilitate comparative studies, and might cure the "no significant difference" syndrome.

Cookson and Chang (1995) drew from previous research and theory in smallgroup interaction analysis, classroom interaction analysis, and audioconferencing to "develop an instrument appropriate for the tabulation, analysis and interpretation" (p. 18) of audioconferences. Gibson (1996) depicted various aspects of academic self-concept as a construct related to persistence, and curbing attrition in distance education.

Also, Gunawardena and Zittle (1997) continued the study Gunawardena had initiated and reported in 1995, and presented further data, adding a more elaborate method of analysis. Likewise, Sherry, Fulford, and Zhang (1998) presented a follow up study to Fulford and Zhang (1993). This continuity in research is noteworthy, since it is rare in the literature of distance education.

\section{Advancing the Field}

Comparative studies were grounded in the physical science paradigm and its related experimental method. They required reduction of experimental concepts to their simplest form, and elimination of environmental elements to establish a direct cause and effect relationship between the experimental stimulus and the

International Review of Research in Open and Distance Learning 
response emitted by the subjects in mass. Furthermore, subjects in these studies were treated as a group, and their individual differences in learning aptitude, and prior knowledge of the subject matter were ignored or eliminated so that the experimental and control groups would be rendered comparable!

Focusing on interaction and looking at learning and other instructional outcomes, such as learner satisfaction, researchers cited above have:

- stepped beyond the experimental method, and its ancillary comparative studies

- grounded their studies on theoretical foundations of the field

- used new methods of inquiry, such as discourse analysis

They have thus made valuable contributions to the field, and have moved research in distance education to higher grounds.

\section{Comprehending the Field}

These efforts in theory-based research, unlike earlier atheoretical comparative studies, reveal the complexity of distance education. The studies mentioned so far were concerned with learning outcomes and interaction in instructional settings. As much as it is central to any educational endeavor, the field of distance education goes beyond instruction, and includes a host of other concerns such as, management and cost-effectiveness, instructional design, evaluation, as well as legal, social and international issues, just to name a few. One of the major challenges of researchers in distance education in the future will be to devise methods of data collection and analysis that correspond to the theoretical complexity of the field.

Starting with the core issue of instructional interaction in distance education, and grounding their study in the theoretical concept of transactional distance, Saba and Shearer (1994) used discourse analysis for data collection, and a systems dynamics simulation method for analyzing the data. A systems method for data analysis was selected in order to be able to respond to the complexity of concepts and variables in distance education. In sharp contrast to the experimental method, systems as a method of inquiry allows researchers to collect data from various sources such as management and legislation, and to study their ramifications on instruction and learning outcomes, as well as several other systems variables. Systems methodology also provides a platform for integrating concepts in hierarchy theory, as well as complexity theory, and for study of learning at a distance as a self-adaptive, non-linear activity of the learner. Based on the 1994 study, these methods are currently being refined to ensure

International Review of Research in Open and Distance Learning 
inclusion of individual differences. It is anticipated that this research will lead to development of personalized, self-adaptive learning systems.

\section{Summary and Conclusions}

Since the 1950s and expansion of social science research, distance education has been studied in comparison to face-to-face or classroom instruction. Although researchers continue to conduct comparative studies, their usefulness in revealing more information has diminished over the years; invariably, they have returned a finding of "no significant difference" between various forms of instruction.

In recent years, researchers have moved beyond experimental comparative studies and have introduced new methods, such as discourse analysis, and in-depth interview of learners. These new methods not only afford a theoretical framework to these studies, something that was lacking in atheoretical comparative studies, they also bypass many methodological and theoretical limitations of the physical science view of distance education.

These studies have further revealed the complexity of distance education, indicating the many variables involved in any instructional setting, not to mention other elements involved in distance education, such as social, economic, and global issues affecting the field.

Starting with the core issue of instructional interaction and grounded on the theory of transactional distance, a new strand of research using methods related to systems dynamics, as well as hierarchy and complexity theories, promises to provide a more comprehensive understanding of the field. 


\section{References}

Best, W. J. (1977). Research in education. (3rd. ed.). Englewood Cliffs, NJ: Prentice-Hall.

Chen, Y-J., \& Willits. F. K. (1999). Dimensions of educational transactions in a videoconferencing learning environment. The American Journal of Distance Education, 13(1), 45-59.

Cookson, P. S., \& Chang, Y. (1995). The multidimensional audioconferencing classification system (MACS). The American Journal of Distance Education, $9(3), 18-36$.

Fulford, C. P., \& Zhang, S. (1993). Perception of interaction: The critical predictor in distance education. The American Journal of Distance Education, $7(3), 8-21$.

Gibson, C. C. (1996). Toward an understanding of academic self-concept in distance education. The American Journal of Distance Education, 10(1), 23-35.

Gunawardena, C. (1995). Social presence theory and implications for interaction and collaborative learning in computer conferencing. International Journal of Educational Telecommunications, 1(2-3), 147-166.

Gunawardena, C. N., \& Zittle, F. J. (1997). Social presence as a predictor of satisfaction within a computer-mediated conferencing environment. The American Journal of Distance Education, 11(3), 8-26.

Johnson, S. D., Aragon, S. R., Shaik, N., \& Palma-Rivas, N. (2000). Comparative analysis of learner satisfaction and learning outcomes in online and faceto-face learning environments. Journal of Interactive Learning Research, 11(1), 29-49.

Machtmes, K., \& Asher, J.W. (2000). A meta-analysis of the effectiveness of telecourses in distance education. The American Journal of Distance Education, 14(1), 27-46.

McDonald, J., \& Gibson, C. C. (1998). Interpersonal dynamics and group development in computer conferencing. The American Journal of Distance Education, 12(1), 7-25.

Moore, M. G. (1989). Three types of transaction. In M. G. Moore, \& G. C. Clark (Eds.), Readings in principles of distance education (pp. 100-105). University Park, PA: The Pennsylvania State University.

Saba, F., \& Shearer, R. L. (1994). Verifying key theoretical concepts in a dynamic model of distance education. The American Journal of Distance 
Education, 8(1), 36-59.

Schramm, W. (1962). What we know about learning from instructional television. In Educational television: The next ten years. Stanford CA: The Institute for Communication Research, Stanford University.

Sherry, A. C., Fulford, C. P., \& Zhang, S. (1998). Assessing distance learners' satisfaction with interaction: A quantitative and a qualitative measure. The American Journal of Distance Education, 12(3), 4-28.

Smith, P. L., \& Dillon, C. L. (1999). Comparing distance learning and classroom learning: Conceptual considerations. The American Journal of Distance Education, 13(2), 6-23.

Tsui, A. B. M., \& Ki, W. W. (1996). An analysis of conference interactions on TeleNex - A computer network for ESL teachers. Educational Technology Research and Development, 44(4), 23-44.

Wetzel. D. D., Radtke, P. H., \& Stern, H. W. (1994). Instructional effectiveness of video media. Hillsdale, NJ: Lawrence Erlbaum Associates.

Citation Format

Saba, Farhad (2000) Research in Distance Education: A Status Report. International Review of Research in Open and Distance Learning: 1, 1. http://www.icaap.org/iuicode?149.1.1.3 